\title{
The effectiveness of common methods of cold-holding on the temperature of milk
}

\author{
Marissa Perrella*, Richard Meldrum*, Melissa T. Moos*and lan Young* \\ *School of Occupational and Public Health, Ryerson University, Toronto, ON, Canada M5B 2K3
}

\begin{abstract}
Keeping self-serve milk below $4^{\circ} \mathrm{C}$ may become difficult for a food premise operator who relies on the use of insulated containers for several hours. Although milk sold in Canada is pasteurized, it may have the potential to cause illness if exposed to improper temperatures. The primary objective of this study was to demonstrate which product would be the most effective at keeping milk cold for the longest period to decrease the potential risk of foodborne illness. A survey was conducted in food premises throughout the Niagara region to determine which products were most commonly used for cold-holding milk, followed by a time-series analysis to investigate how rapidly the temperature of milk increased when stored in typical containers after 8 hours. Results showed that vacuum-insulated carafes are the most effective at cold-holding and stainless-steel carton holders are the least effective. The Niagara survey showed that 8 of 27 premises visited used these poorly insulated stainless-steel carton holders, which may be additionally susceptible to human contamination from potentially pathogenic bacteria such as Staphylococcus aureus due to their open spout.
\end{abstract}

Key words: milk, cold-holding, carafe, insulation, food premise, staphylococcus aureus.

\section{Introduction}

Food premises that sell coffee and tea sometimes rely on the use of thermal containers to keep milk cold for several hours at a time. Although milk in Canada is pasteurized before sale, it still has the potential to be a low-risk hazard that may cause foodborne illness if exposed to improper temperatures. Previous studies have shown that when milk is kept at room temperature, the shelf-life is cut in half (Zahar et al., 1996). Typically, only refrigerators can hold a constant cold temperature; however, this method is often not practical for food premises that have selfserve stations for coffee and tea. Many products claim they can keep contents cold for 6-24 hours, but without specific temperature details, further investigation is needed to determine if this is within the safe hold range for milk.

Milk has become an essential part of the human diet since the early domestication of mammals and requires a great deal of processing before it is safe to consume. Milk is exposed to several different sources of contamination along its production chain, including the cow itself, the environment, and the milking equipment (Griffiths, 2010), and without any type of heat treatment, milk is a perfect growth medium for many pathogens. If milk is kept below $5{ }^{\circ} \mathrm{C}$, then these pathogens are unable to grow. A general rule for pasteurized milk is that every $2{ }^{\circ} \mathrm{C}$ increase in temperature reduces the expiry date by $50 \%$ (Rysstad \& Kolstad, 2006).

Corresponding author: Marissa Perrella (email: marissa.a.perrella@ gmail.com)
Meurant (1995) states that ideally milk should be chilled at refrigerator temperatures $\left(4{ }^{\circ} \mathrm{C}\right.$ or less according to the Canadian Food Inspection Agency, 2014) at all times to decrease bacterial growth. Staphylococcus aureus is a common and important bacterium that may cause foodborne illness; in milk it can produce toxins when the temperature exceeds $15^{\circ} \mathrm{C}$ (Griffiths, 2010). Bacillus cereus is also of concern since its spores can survive pasteurization and begin growth at $10{ }^{\circ} \mathrm{C}$. Deeth et al. (2002) determined that there is no important difference between the spoilage bacteria that grow in skim milk compared with whole milk, so both types of milk were treated as equal during this study.

The primary objective of this study was to determine which product would be the most effective at keeping milk cold for the longest period. In doing so, the most adequate method should further be recommended by public health inspectors to food premises operators to decrease the likelihood of foodborne illness due to temperature abuse. The secondary objective was to assess the food handling procedures of staff at different food premises regarding the length of time that they had been storing milk at room temperature.

While no bacterial count was conducted, it was important to consider the final temperatures of the milk in different coldholding products after 8 hours in terms of the potential for bacterial growth. In addition, it is important to consider external contamination sources that may pose a risk to the safety of the milk. This study will allow public health inspectors to recommend the most effective methods of cold-holding milk for at-risk premises. 


\section{Methods}

\section{Preliminary field study}

Preliminary steps were done in collaboration with Niagara Region Public Health. The field study was done to collect preliminary data on which products were most commonly used in various types of food premises in the region. In October 2016, a mix of 59 cafes, convenience stores, hotels, cafeterias, and restaurants throughout Niagara region were selected and visited based on their likelihood to be using external methods of cold-holding milk. Student public health inspectors visited each location between 10:00 AM and 3:00 PM, verifying the premise had been open and running for at least 2 hours. The temperature of milk was recorded in each container and the type of container was recorded. Investigators also asked the operators how long the milk had been out of the fridge for and provided a consent form stating that the premise names would not be disclosed in this study. These data were used to determine whether the food handlers were practicing good food handling procedures in regard to changing the milk and maintaining it at an adequate temperature.

\section{Laboratory experiment}

The second part of the study was conducted at Ryerson University using a time-series analysis to determine which product was the most effective at cold-holding milk. From the preliminary survey data, three products were determined to be the most common: a $1 \mathrm{~L}$ vacuum-insulated carafe, a $1 \mathrm{~L}$ stainless steel milk box, and a 1.5 L foam-insulated plastic jug (Figure 1). To begin, four $1 \mathrm{~L}$ cartons of $1 \%$ pasteurized milk with the same expiry date were purchased and stored under regular refrigeration temperatures. The ambient room temperature was measured. Three $1 \mathrm{~L}$ cartons of milk were poured or placed into their designated containers, and the fourth remained on its own as a control. The initial temperature of each of the four milk products was taken and recorded immediately, and for every 30 minutes following, the temperature was recorded for a total of 8 hours. Ambient room temperature was also recorded again at the fourth and eighth hour. This experiment was repeated twice.

\section{Product background information}

The first most commonly used product was a stainless-steel vacuum carafe, the installation of a vacuum flask into a carafe is what
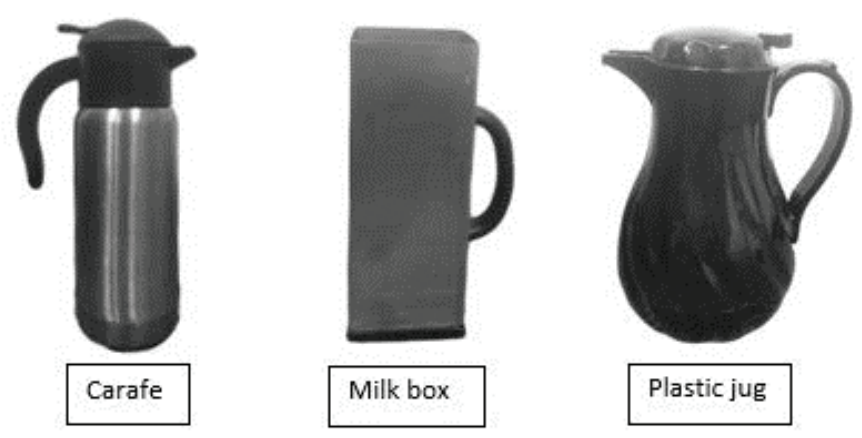

Figure 1. Containers used in this study: carafe, milk box, and foaminsulated jug. makes the carafe effective at keeping its contents either hot or cold. As explained by Applin et al. (2003), the inside of a vacuum flask consists of two walls that do not allow air in between them, therefore creating a vacuum. The walls are often made of glass which is a poor conductor of heat, therefore eliminating excess heat conduction transfer. Because the air is cut out, it is no longer possible to form convection currents so energy is not lost. The second most common product was a stainless-steel milk carton holder, or "milk box," used to hold $1 \mathrm{~L}$ cartons of milk. While the vacuum insulated carafes are completely sealed at all times, milk boxes only shield the four sides of the carton and the bottom, leaving the top wide open. McGuire and Deuschle (2015) explained that due to its high reflectance and low emissivity, stainless steel can repel solar warming and minimize energy loss in the structure. The third common product used to cold-hold milk had foam insulation instead of vacuum insulation. Most insulated jugs meant for holding liquids consist of polyurethane foam due to its thermal insulation properties, the foam fills the space entirely thereby removing air (Szycher, 1999).

\section{Results}

\section{Survey data}

Overall, 59 premises were visited throughout the Niagara region in October 2016. Of these, 32 premises used external methods of cold-holding milk; five declined the survey, whereas the other 27 used refrigeration or milkettes/milk cups instead. In total, 27 different premises participated in the survey and contributed to the data. Most of the premises that used external methods of cold-holding were cafes, followed by hotels and cafeterias, and even fewer grocery stores, restaurants, or convenience stores. Sixteen of 27 premises used $1 \mathrm{~L}$ vacuum-insulated thermal carafes, eight of 27 used $1 \mathrm{~L}$ stainless steel milk boxes and three of 27 used 1.5 or $2 \mathrm{~L}$ foam-insulated plastic jugs (Table 1 ).

The next results were based on the recall question asked during the preliminary survey: "how long has the milk been out of the refrigerator?" The 36 temperature recordings from 27 different premises were inputted in rows corresponding to the time that the operator stated the milk had been left out for. The average survey-recorded temperatures (including all types of containers) were calculated for each time interval of 30 minutes

Table 1. Breakdown of the different types of food premises visited and the types of products that they were using to keep milk cold.

\begin{tabular}{|l|c|c|c|c|}
\hline & $\begin{array}{c}\text { Vacuum } \\
\text { carafe } \\
\text { (1 L) }\end{array}$ & $\begin{array}{c}\text { Milk box } \\
(\mathbf{1} \text { L) }\end{array}$ & $\begin{array}{c}\text { Other } \\
(\mathbf{1 . 5}-\mathbf{2} \text { L) }\end{array}$ & Total \\
\hline Café & 14 & 2 & & 16 \\
\hline Hotel & 2 & 1 & 1 & 4 \\
\hline $\begin{array}{l}\text { Convenience } \\
\text { store }\end{array}$ & - & 1 & - & 1 \\
\hline Cafeteria & - & 3 & 1 & 4 \\
\hline Restaurant & - & - & 1 & 1 \\
\hline Grocery store & - & 1 & - & 1 \\
\hline Total & 16 & 8 & 3 & 27 \\
\hline
\end{tabular}




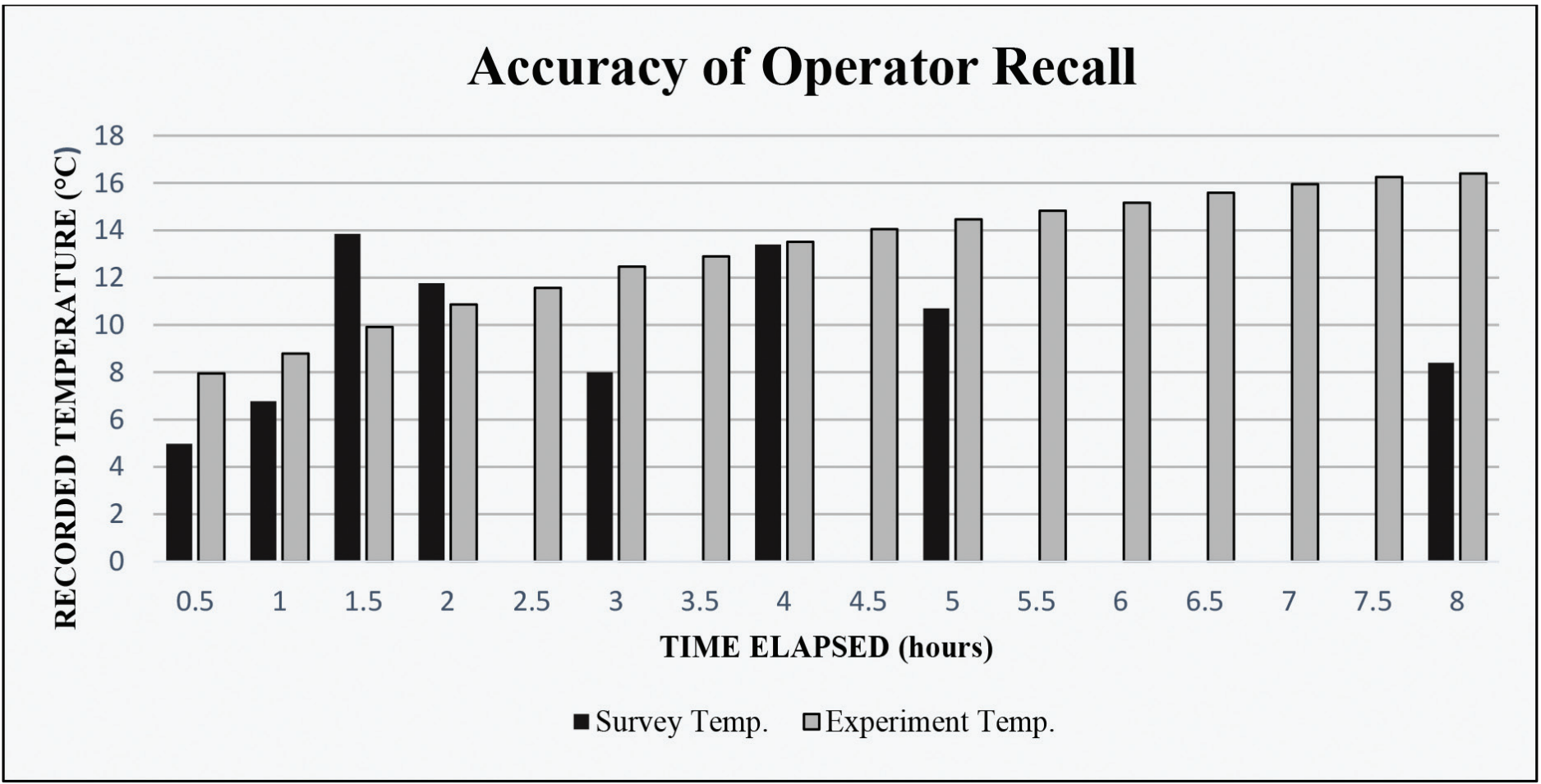

Figure 2. Average recorded temperature from operator recall compared with average recorded temperature from the actual time-temperature experiment.

and are presented in Figure 2. To compare, the average experiment-recorded temperature at each 30-minute interval was determined, which included the temperatures at each interval for all three milk containers from both experiments. The average experiment-recorded temperature is therefore the more accurate data reflection of milk temperature after a specified amount of time (Figure 2).

\section{Lab experiment data}

These results were derived from the time-temperature experiment by measuring the temperature of each of the containers of milk plus the control over 30-minute intervals for 8 hours. Each container of milk started the experiment between $6.5^{\circ} \mathrm{C}$ and 7.5 ${ }^{\circ} \mathrm{C}$ at a room temperature of $19.3^{\circ} \mathrm{C}$ (Figure 3). At the 4-hour mark, the vacuum insulated carafe temperature rose from $6.5^{\circ} \mathrm{C}$ to $8.4^{\circ} \mathrm{C}$, the milk box temperature rose from $7.4^{\circ} \mathrm{C}$ to $15.6^{\circ} \mathrm{C}$, and the foam-insulated jug rose from $6.7^{\circ} \mathrm{C}$ to $12^{\circ} \mathrm{C}$ (Figure 3 ). At this point, the vacuum-insulated carafe displayed the strongest thermal insulation properties. Overall, the temperature of the milk in the vacuum-insulated carafe rose from $6.5^{\circ} \mathrm{C}$ to 10.3 ${ }^{\circ} \mathrm{C}$ (a $3.8^{\circ} \mathrm{C}$ increase) after 8 hours, the milk box temperature rose from $7.4^{\circ} \mathrm{C}$ to $18.5^{\circ} \mathrm{C}$ (an $11.1^{\circ} \mathrm{C}$ increase), and the foaminsulated jug temperature rose from $6.7^{\circ} \mathrm{C}$ to $15.3^{\circ} \mathrm{C}$ (an $8.6^{\circ} \mathrm{C}$ increase) (Figure 3). In comparison with the control which increased a total of $13^{\circ} \mathrm{C}$ after 8 hours, the milk box only kept its contents $\sim 2{ }^{\circ} \mathrm{C}$ cooler.

Very similar data were derived from the second temperature test; ambient room temperature began at $21.1^{\circ} \mathrm{C}$ and finished at $22.6^{\circ} \mathrm{C}$ (Figure 4). After 8 hours, the vacuum-insulated carafes milk temperature rose $3.8^{\circ} \mathrm{C}$, the milk box temperature rose $12.8^{\circ} \mathrm{C}$, the foam-insulated jug temperature rose $10.1{ }^{\circ} \mathrm{C}$, and the control temperature rose $14.7^{\circ} \mathrm{C}$ (Figure 4). Once again, the vacuum-insulated carafe was the most effective cold-holding product.

\section{Discussion and recommendations}

It was determined the temperature of milk recorded in the survey was on average lower than the temperature of milk taken during that same interval during the actual lab experiment, indicating the operators were accurate in estimating time of use for countertop milk containers and were therefore likely practicing good food handling by changing the milk frequently to avoid extensive temperature abuse.

Results of the two independent experiments suggest stainless-steel milk carton holders or "milk boxes" are not effective to maintain safe temperatures of milk when kept out of the refrigerator. In addition, these carton holders allow the milk to be fully exposed to contamination from users which can increase the risk of potential foodborne illness due to pathogenic growth. Products with foam insulation proved to be more effective at cold-holding when compared with the milk box; however, it was the vacuum-insulated carafe that was the most sufficient in maintaining milk at a cold internal temperature for an extended period when out of refrigeration. While results showed that most operators and staff appeared to be practicing safe food handling practices by only allowing their self-serve milk to be out at room temperature for a limited period, no data were recorded regarding how these containers were cleaned and sanitized between uses.

Until 2001, Part III, Section 30 of Ontario Regulation 562 under the Health Protection and Promotion Act stated that milk had to be served either in its original container only at all times or could alternatively be given to a seated patron in a single serving 


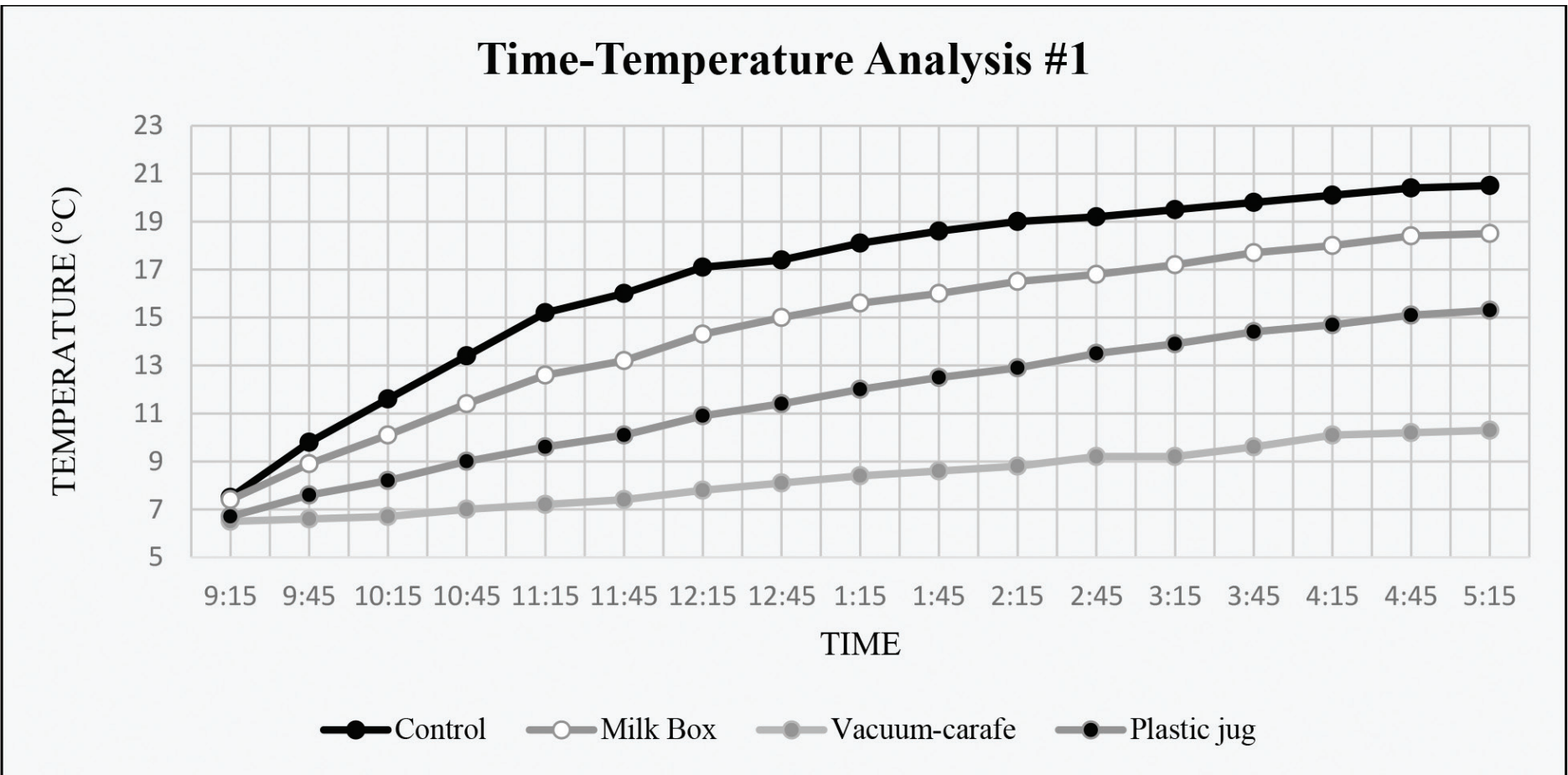

Figure 3. The first time-temperature experiment data, taken over an 8-hour period. The vacuum-carafe kept the milk the coolest while the milk box proved to be the least effective.

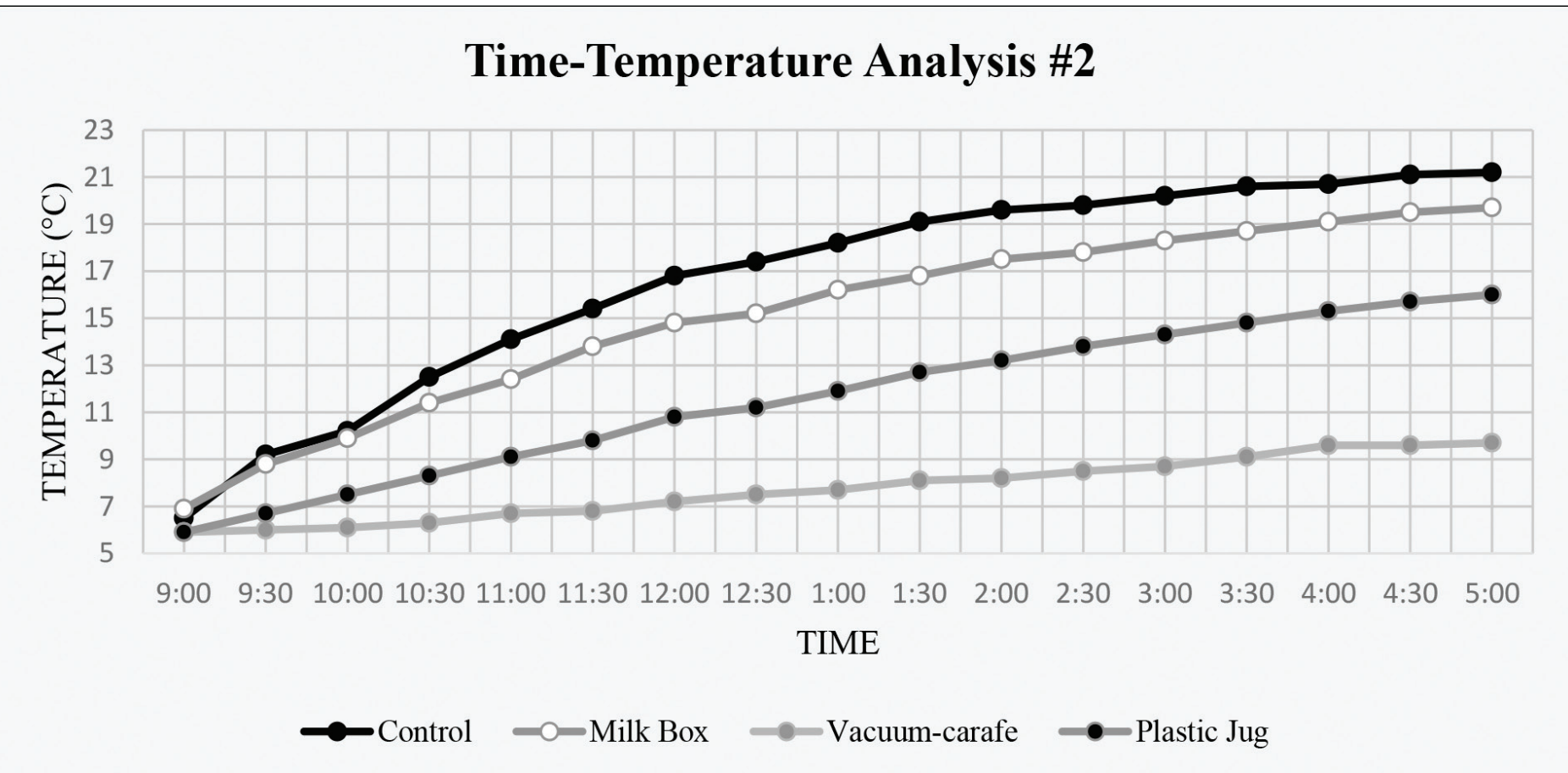

Figure 4. The second time-temperature experiment data, taken over an 8-hour period. The vacuum-carafe kept the milk the coolest while the milk box proved to be the least effective.

to add to their food or drink. The milk box would have therefore been the only acceptable method of cold-holding because the milk remains in its original container, but as this study has shown it is very ineffective. On 26 April 2001, the Ontario Ministry of
Health and Long-Term Care published an exemption to allow for the use of vacuum-insulated thermal carafes that were able to meet all of the qualifications as follows (MOHLTC, 2001): be certified by the National Sanitation Foundation (NSF), all parts 
must be dishwasher safe, and be capable of holding the temperature of cream or milk so as not to exceed $2.8^{\circ} \mathrm{C}$ above the required $5^{\circ} \mathrm{C}$ over a period of 6 hours at a room temperature of $20^{\circ} \mathrm{C}$

In addition, the thermos must only ever be filled with cream or milk from the original container, be used only to dispense cream or milk as an addition to beverages and cereals, and must be washed, rinsed, and sanitized as required before it is refilled or at least every 6 hours while in use (MOHLTC, 2001). An important note to make about this exemption is that not all premises in Niagara region were in compliance, as three of 27 still used foam-insulated thermal carafes that are not vacuuminsulated, are not NSF certified, and cannot hold milk under the specific temperature range qualifications.

While there are some thermoduric psychrotrophs that may grow in milk that has been contaminated, several of them (such as Paenibacillus) are not actually harmful to human health (Cornell University, 2010). Both Salmonella Typhimurium and Escherichia coli have been frequently linked to outbreaks in pasteurized milk due to post-treatment contamination and temperature abuse; however, this typically happens in the processing plant after treatment and is caused by human error (Langer et al., 2012). Conversely, additional pathogenic microorganisms that may be spread to milk from patron contamination exist, and it is more likely that milk left out on a table for public use may become contaminated by consumers before spoilage microorganisms grow. While high turnover rates may prevent temperature abuse of the milk, the more people that use the milk, the more likely it is to get contaminated via sneezing, coughing, or touch contamination.

The main pathogen of concern for contamination from consumers to milk is $S$. aureus. According to Freeman-Cook et al. (2006), it is estimated that $10 \%-40 \%$ of human adults are carriers of $S$. aureus. Humans are the only reservoirs of $S$. aureus, as our mucous membranes provide the perfect habitat for growth since the bacteria grows over a wide temperature range beginning at as low as $15^{\circ} \mathrm{C}$ (Freeman-Cook et al., 2006). Therefore, milk that has experienced temperature abuse and staphylococcal contamination from a user can support growth when stored in roomtemperature conditions. Toxins created from $S$. aureus bacteria can cause food poisoning that typically has a rapid onset of severe cramps, nausea, vomiting, and diarrhea (Freeman-Cook et al., 2006). According to the Centre for Disease Control (2016), foods that are at a higher risk for being contaminated with $S$. aureus include those that are handled and not cooked after, such as milk. Staphylococcal food poisoning typically only lasts 1 day; therefore, it often goes underreported, so it is difficult to predict how many people experience this illness yearly (CDC, 2016).

To prevent potential pathogenic growth due to both temperature abuse and contamination of milk from consumers, ultrahigh temperature (UHT) treated milk cups, or milkettes, can be considered as a safer and more effective single-serve alternative. UHT treatment of milk involves heating it to extremely high temperatures (about $135^{\circ} \mathrm{C}$ ) for a few seconds, followed by rapid cooling and aseptic packaging into sterile containers (Sun, 2012). UHT treatment produces a commercially sterile milk with zero pathogenic microorganisms remaining; therefore, these products have a much longer shelf life (up to 6 months without refrigeration) than pasteurized milk (Caballero et al., 2015). The downfall to promoting the use of milkettes is that they are not environmentally friendly as they are made from plastic as opposed to milk cartons, which are made from recyclable cardboard.
Upon updating Ontario Regulation 562, attention should be paid to section 30 regarding specific details for products and methods that can or cannot be used for cold-holding milk. For example, stainless-steel milk boxes with the open-concept spout should not be permitted for use as they allow for potential contamination from users and provide very little insulation to the milk itself. These boxes put the milk at risk for becoming a potential health hazard due to their design. The carafe requirements listed in the 2001 exemption written by the Ontario Ministry of Health and Long-Term Care should be directly implemented into Ontario Regulation 562. More detail should also be provided in the Regulation regarding how frequently the milk should be changed or discarded and how carafes are to be cleaned and sanitized. In addition, the use of UHT treated milkettes should be further explored and potentially enforced as an alternative method.

\section{Conclusion}

This study determined that vacuum-insulated thermal carafes display excellent insulation properties and are therefore the most effective at keeping milk cold for an extended period of time. Because of this finding, public health inspectors should encourage their food premises operators to use these containers where applicable. It was also found the food handling practices of staff at various food premises appeared to be adequate regarding how frequently they were changing out the milk to avoid extensive temperature abuse. Foam-insulated containers are not accepted by the Regulation; however, some food premises continue to use them. While milk boxes are permitted under the Regulation, they have poor insulation properties and expose milk to a higher risk of consumer contamination. The results of this study suggest that the Regulation may need to be amended to prohibit the use of milk boxes while additionally requiring the use of specific vacuum-insulated thermal carafes.

\section{Acknowledgements}

Thank you to the staff at Niagara Region Public Health who made this research possible by contributing to the very essential preliminary data.

\section{References}

Applin, D. G., Breithaupt, J., and Ramsden, E. 2003. Metals. In AQA modular science for GCSE, pp. 205-207. Cheltenham, UK: Nelson Thornes.

Caballero, B., Finglas, P., and Toldra, F. 2015. Milk: Processing of milk. In Encyclopedia of food and health, Vol. 1, pp. 731-732. Amsterdam: Academic Press.

Canadian Food Inspection Agency. 2014. Guide to food safety. Available at: http://www.inspection.gc.ca/food/non-federally-registered/safe-food-production/guide/eng/1352824546303/135282 4822033

Centre for Disease Control (CDC). 2016. Staphylococcal food poisoning. Available at: https://www.cdc.gov/foodsafety/diseases/ staphylococcal.html [accessed 24 May 2017]. 
Cornell University. 2010. Psychrotrophic spore-forming bacteria in raw and pasteurized milk. In Dairy foods science notes, pp. 1-2. Ithaca, NY: Cornell University Publishing.

Deeth, H. C., Khusniati, T., Datta, N. and Wallace, R. B. 2002. Spoilage patterns of skim and whole milks. J. Dairy Res. 69: 227-241.

Freeman-Cook, L., Freeman-Cook, K. D., and Edward-Alcamo, I. 2006. Staphylococcus aureus infections, pp. 28-41. Philadelphia, PA: Chelsea House.

Griffiths, M. 2010. Improving the safety and quality of milk, Vol. 1, pp. 3-91. Oxford: Woodhead Publishing.

Health Protection and Promotion Act, 562 C.F.R $₫ 30$ (1990).

Langer, A., Ayers, T., Grass, J., Lynch, M., Angulo, F. and Mahon, B. 2012. Nonpasteurized Dairy products, disease outbreaks, and state laws-United States, 1993-2006. Emerg. Infect. Dis. J. 18: 385-391.

Meurant, G. 1995. Sampling and storage of human milk. In Handbook of milk composition, pp. 72-76. CA: Academic Press.
McGuire, M. and Deuschle, F. 2015. The insulation value of stainless steel. Available at: http://www.metalresources.net/index.php/save-energy/ 243-the-insulation-value-of-stainless-steel [accessed 6 March 2017].

Ministry of Health and Long Term Care (MOHLTC). 2001. Serving cream and milk from a container other than the original. Food Premises Regulation, Oat. Reg 562 RRO, 2990. Reference Subsection 30 (3) [Letter to ALL MEDICAL OFFICERS OF HEALTH]. (2001, April 26). Toronto, ON: Public Health Branch.

Rysstad, G. and Kolstad, J. 2006. Extended shelf life milk-advances in technology. Int. J. Dairy Technol. 59: 85-95.

Sun, D. 2012. Thermal processing of dairy products. In Thermal food processing: New technologies and quality issues, 2nd ed., pp. 289290. FL: CRC Press.

Szycher, M. 1999. Introduction. In Szycher's handbook of polyurethanes, 2nd ed., pp. 6-9. FL: CRC Press.

Zahar, M., Tatini, S. R., Hamama, A. and Fousshi, S. 1996. Effect of storage temperature on the keeping quality of commercially pasteurized milk. Actes. Inst. Agron. Veto (Maroc). 16: 5-10. 